RESEARCH REPORT

\title{
Educational level and risk profile of cardiac patients in the EUROASPIRE II substudy
}

\author{
O Mayer Jr, J Šimon, J Heidrich, D V Cokkinos, D De Bacquer on behalf of EUROASPIRE II study \\ group
}

J Epidemiol Community Health 2004;58:47-52

See end of article for authors' affiliations

Correspondence to:

Dr O MayerJr, University

Hospital, 2nd Department

of Internal Medicine, $13 \mathrm{E}$

Beneše Street, 32000

Plzeň, Czech

Republic;mayerir@

Ifp.cuni.cz

Accepted for publication

5 May 2003

Study objective: To ascertain, whether, conventional risk factors and readiness of coronary patients to modify their behaviour and to comply with recommended medication were associated with education in patients with established coronary heart disease.

Design and methods: EUROASPIRE II was a cross sectional survey undertaken in 1999-2000 in 15 European countries to ascertain how effectively recommendations on coronary preventions are being followed in clinical practice. Consecutive patients, men and women $\leqslant 71$ years who had been hospitalised for acute coronary syndrome or revascularisation procedures, were identified retrospectively. Data were collected through a review of medical records, interview, and examination at least six months after hospitalisation. The education reached was ascertained at the interview.

Main results: A total of 5556 patients (1319 women) were evaluated. Significantly more patients with ischaemia had only primary education, in contrast with the remaining diagnostic groups. Body mass index and glucose were negatively associated with educational level, while HDL-cholesterol was positively associated. Men with highest education had significantly lower systolic blood pressure and total cholesterol. The prevalence of current smoking decreased significantly from primary to secondary and high education only in men. Both men and women with primary educational level were more often treated with antidiabetics, and antihypertensives, but less often with lipid lowering drugs. The effectiveness of treatment was virtually the same in all education groups.

Conclusions: Patients with higher education had lower global coronary risk, than those with lower education. This should be considered in clinical practice. Particular strategies for risk communication and counselling are needed for those with lower education status.

S ocioeconomic status (SES) is believed to be important in influencing the development of coronary heart disease (CHD). SES is a very complex phenomenon predicted by a broad range of variables, mainly combining the influences of education and occupation. ${ }^{1}$ Higher education virtually enables to reach higher SES and access to positive, social, cultural, psychological, and economic resources. Over time, education has become the most commonly used measure of SES in epidemiological studies. $^{2-5}$ These studies have shown an inverse relation between education and lifestyle related risk factors, as well as long term risk of CHD, cardiovascular disease, and all cause mortality. ${ }^{267}$ It has been also shown, that among such measures of SES, as education, income and occupation, low level of education was most consistently associated with higher coronary risk. ${ }^{2}{ }^{3}$ High SES has been supposed as a predictor of good health. ${ }^{1}$ The influence of education on coronary risk factors and their control after acute coronary syndromes has not yet been thoroughly studied. Diagnostic studies in patients with CHD mostly included social support, job control demands, anxiety, depression, hostility and anger, as SES measures. ${ }^{8}$ The EUROASPIRE (European action on secondary prevention by intervention to reduce events) studies $^{910}$ were primary aimed to ascertain how the European Guidelines on secondary prevention ${ }^{11}$ were implemented in different European countries. It also offered a unique opportunity to assess the extent to which educational status was associated with biomedical and lifestyle risk factors, the implementation of behavioural changes and pharmacotherapies, recommended by European guidelines. ${ }^{11}$

\section{METHODS}

\section{Sample selection and data collection}

The design and the protocol of the EAII study are described in detail elsewhere. ${ }^{9}$ The survey was undertaken in 1999-2000 in 15 European countries-Belgium, Czech Republic, Finland, France, Germany, Greece, Hungary, Ireland, Italy, the Netherlands, Poland, Slovenia, Sweden, Spain, and UK. Within each country one or more geographical areas with a defined population (greater than half a million people) was selected and all hospitals serving this population were identified. The area included at least one hospital offering interventional cardiology and cardiac surgery, and one or more hospitals receiving patients with acute myocardial infarction and ischaemia. A sample of one or more hospitals, or all hospitals, was taken so that any patient presenting within the area with acute symptoms of coronary disease, or requiring revascularisation in the form of balloon angioplasty or coronary artery surgery, had an approximately equal chance of being included. Patients admitted to a hospital outside this geographical area were not included in the sample. Within each hospital consecutive patients, men and women $\leqslant 70$ years of age at the time of the index event or procedure, with the following diagnoses or treatments for coronary disease (see below) were identified from diagnostic registers, hospital discharge lists or other sources:

Abbreviations: SES, socioeconomic status; CHD, coronary heart disease; $C A B G$, coronary artery bypass graft; $A M I$, acute myocardial infarction; PCTA, percutaneous transluminal coronary angioplasty; EAll, EUROASPIRE ॥ 


\section{Key points}

- Education level was shown to be a good estimate of socioeconomic status, associated with increased coronary mortality and morbidity

- In a secondary prevention setting, low education status is associated with higher risk profile and poor compliance to both, behavioural and pharmacological interventions.

\section{Coronary artery bypass graft (CABG)}

Consecutive patients having their first elective or emergency CABG operation, including emergency CABG for AMI were identified from the hospital surgical registers or other sources. All first operations for coronary artery disease were included. When coronary artery surgery was performed in the context of valve replacement or when the primary diagnosis was not coronary artery disease, patients were excluded.

\section{Percutaneous transluminal coronary angioplasty (PTCA)}

Consecutive patients following their first elective or emergency PTCA, including emergency PTCA for AMI were identified from the catheter laboratory registers or other sources. The term PTCA included all first procedures as well as the use of stents and other devices. Patients with a history of CABG were excluded.

Acute myocardial infarction (AMI: ICD-9 410)

Consecutive patients with a hospital diagnosis of first or recurrent AMI but no history of CABG or PTCA were identified from the cardiac care unit admission or hospital discharge books, death returns, or other sources.

\section{Acute myocardial ischaemia (ischaemia: ICD-9 411,} 413)

Consecutive patients with a hospital diagnosis of first or recurrent acute myocardial ischaemia but no evidence of infarction, and no history of CABG, PTCA or a previous AMI were identified from the cardiac care unit admission or hospital discharge books, death returns, or other sources.

Consecutive patients were identified retrospectively, including those who died during their surgical procedure or in-hospital stay, but no earlier than l January 1997. Although some hospital diagnoses for AMI and ischaemia might not always meet the standard diagnostic criteria used by WHO, all cases with these diagnostic labels were included, as all these patients should be appropriately managed in relation to lifestyle intervention, management of other risk factors, and use of prophylactic drug treatments.

The data collection took place at least six months after the date of acute hospital admission or procedure and was based on a review of medical records and an interview and examination of the patients. Within each country the objective was to obtain information from a minimum of 400 living patients attending for an interview: 100 CABG, 100 PTCA, 100 AMI, and 100 ischaemia. To allow for deaths and non-response to invitation for interview, a sample of at least 525 consecutive patients had to be drawn: 150 for acute myocardial infarction (which has a larger number of inhospital deaths than the other categories) and 125 in each of the other three diagnostic groups.

\section{Patient interview and examination}

The responders were interviewed and examined by trained staff, using standardised methods and instruments at least six months after their admission for index acute coronary event or revascularisation procedure. The study procedures were done according to good clinical practice regulation and were approved by local ethical committee. Informed consent was obtained from all subjects. Information of personal and demographic characteristics, personal and family history of coronary heart disease, lifestyle advice and current pharmacotherapy were obtained at interview. Number of years spent at school and the highest education degree obtained were recorded. The following measurements were performed: height and weight were measured in light indoor clothes without shoes using SECA 707 scales and measuring stick. Body mass index (BMI) was calculated as weight $(\mathrm{kg})$ / height $(\mathrm{m})^{2}$. Blood pressure (BP) was measured twice in the sitting position on the right arm using an automatic digital sphygmomanometer (Omron 711) and the mean of two measurements was used for data analyses. Reported current smoking status was verified, using breath carbon monoxide measurement by Smokerlyser (model EC 50 Mikro III, Bedfont Scientific, UK). All used devices (scales, sphygmomanometers, and smokerlysers) were calibrated at the start of survey using appropriate standard procedures and by manufacturer's reference. Venous blood samples were drawn in fasting state and serum or plasma was separated. The aliquots were stored at the local centres until they were shipped in solid carbon dioxide to the central laboratory (central laboratory at the Department of Medicine, University of Manchester, UK). The laboratory examinations included estimation of total cholesterol (TCHOL) and HDL cholesterol (HDL), triglycerides (TG), glucose (GLU). Serum was used for the measurement of TCHOL, HDL and TG using Unimate 7 cholesterol, Unimate HDL Direct and Unimate triglyceride reagents (Roche Diagnostics) on a Cobas Mira S Autoanalyser (Roche Diagnostics). LDL cholesterol was calculated by Friedewald equation-LDL $=\mathrm{TCHOL}-\mathrm{HDL}-(\mathrm{TG} / 5)$. The non-fasting subjects were excluded from LDL calculation. During the course of the study the coefficient of variation for TCHOL cholesterol was $1.2 \%$, for HDL cholesterol $9.4 \%$ and for TG $2.1 \%$. Plasma GLU was measured from lithiumheparin samples using the hexokinase method (Bayer) on a Bayer Axon analyser. Coefficient of variation for glucose measurements was $2.8 \%$.

\section{Data management and statistical analyses}

All data were stored electronically onto notebook computers using a unique identification number for country, centre, and individual. Data were sent to the coordinating centre (Cardiac Medicine, National Heart and Lung Institute, University of London), where they were checked for completeness, internal consistency, and accuracy. All data were stored under the provisions of the United Kingdom Data Protection Act.

Patients were divided into three educational groups: primary education defined as primary school or less, secondary education characterised as secondary school level, and high education defined as university/college levels or equivalent. The differences in national educational systems were taken into account. The median of years spent at school varied necessarily for education level reached among participating countries from 10 years for primary education in Czech Republic and Ireland, to six years in Finland and Greece, and only four years in Spain. To reach highest education level (university or college), the median of 14-17 years were necessary in most countries. Risk factors were categorised as follows: smoking $=$ self reported smoking or carbon monoxide in breath $>10 \mathrm{ppm}$; raised blood pressure $=$ systolic $\quad \mathrm{BP} \geqslant 140 \mathrm{~mm} \quad \mathrm{Hg}$ and/or diastolic $\mathrm{BP} \geqslant 90 \mathrm{~mm} \mathrm{Hg}$; high total cholesterol $=\mathrm{TCHOL} \geqslant 5 \mathrm{mmol} / \mathrm{l}$; low $\mathrm{HDL} \quad$ cholesterol $=\mathrm{HDL}<1 \mathrm{mmol} / \mathrm{l} ; \quad$ overweight $=$ 
Table 1 Prevalences of educational level by diagnosis, gender, and age

\begin{tabular}{|c|c|c|c|}
\hline & \multicolumn{3}{|l|}{ Educational level } \\
\hline & Primary* & Secondary† & High $\ddagger$ \\
\hline All & $40.0 \%(2206 / 5519)$ & $34.0 \%(1877 / 5519)$ & $26.0 \%(1436 / 5519)$ \\
\hline \multicolumn{4}{|l|}{ By diagnosis: } \\
\hline CABG & $36.0 \%(510 / 1415)$ & $35.4 \%(501 / 1415)$ & $28.6 \%(404 / 1415)$ \\
\hline PTCA & $38.0 \%(590 / 1552)$ & $35.9 \%(557 / 1552)$ & $26.1 \%(405 / 1552)$ \\
\hline AMI & $40.1 \%(582 / 1450)$ & $34.4 \%(499 / 1450)$ & $25.4 \%(369 / 1450)$ \\
\hline Ischaemia & $47.6 \%(524 / 1102)$ & $29.0 \%(320 / 1102)$ & $23.4 \%(258 / 1102)$ \\
\hline \multicolumn{4}{|l|}{ By gender: } \\
\hline Men & $36.6 \%(1544 / 4217)$ & $34.4 \%(1452 / 4217)$ & $29.0 \%(1221 / 4217)$ \\
\hline Women & $50.8 \%(662 / 1302)$ & $32.6 \%(425 / 1302)$ & $16.5 \%(215 / 1302)$ \\
\hline \multicolumn{4}{|l|}{ By age groups: } \\
\hline$\leqslant 60$ years & $33.2 \%(855 / 2576)$ & $38.2 \%(985 / 2576)$ & $28.6 \%(736 / 2576)$ \\
\hline$>60$ years & $45.9 \%(1351 / 2943)$ & $30.3 \%(892 / 2943)$ & $23.8 \%(700 / 2943)$ \\
\hline
\end{tabular}

$\mathrm{BMI} \geqslant 25 \mathrm{~kg} / \mathrm{m}^{2} ; \quad$ obesity $=\mathrm{BMI} \geqslant 30 \mathrm{~kg} / \mathrm{m}^{2} ; \quad$ diabetes $=$ self reported or plasma GLU levels $\geqslant 7 \mathrm{mmol} / \mathrm{l}$ (used cut off points recommended by the European Recommendations ${ }^{11}$ ).

All statistical analyses were undertaken using SAS statistical software in the Department of Public Health, Ghent University, Belgium. Differences in continuous variables between educational groups were statistically evaluated through analysis of covariance with adjustment for age and gender. Natural logarithmic transformations were used were necessary. Adjusted differences in proportions were analysed according to logistic regression modelling. From the logistic models, adjusted odds ratios (OR) and 95\% confidence intervals (CI) were calculated.

\section{RESULTS}

\section{Sample structure}

In total, 8181 medical records were reviewed and 5556 patients were interviewed on average 1.4 years after the index event. The participation rate for interview among those, who were contacted and found alive, was $76 \%$. The distribution of educational level by diagnostic group, gender, and age is presented in table 1. The proportion of primary, secondary, and high educational level in the whole sample was $40 \%, 34 \%$, and $26 \%$, respectively.
Significantly more patients with ischaemia had only primary education, and proportionally fewer had secondary and high education, in contrast with the remaining diagnostic groups $(\mathrm{p}<0.0001)$. The distribution of education levels among remaining diagnostic groups was similar. There were significantly more women than men with only primary education and proportionally more men than women with highest education $(\mathrm{p}<0.0001)$. Comparing the age structure among educational groups, significantly more patients over 60 years had only primary education group and proportionally fewer had secondary and high education. $(\mathrm{p}<0.0001)$.

\section{Risk profile of the patients}

Distribution of quantitative coronary risk factors in men and women is given in table 2. Generally, men and women with high and secondary education were younger than patients with only primary education. There was a clear, significant, negative trend from primary to secondary and high education, in BMI and glucose, but a positive trend in HDL, in both sexes. In addition, men with high education had significantly lower systolic BP and TCHOL. The lowest diastolic BP was found in men with primary education.

Distribution of categorical risk factors is shown in table 3. Again, there were clear, significant negative trends from

Table 2 Mean (SD) values of coronary heart disease risk factor measurements by educational level and gender

\begin{tabular}{|c|c|c|c|c|}
\hline & \multicolumn{3}{|c|}{ Educational level } & \multirow[b]{2}{*}{ p Value* } \\
\hline & Primary & Secondary & High & \\
\hline \multicolumn{5}{|l|}{ Men } \\
\hline Age $(y$, mean (SD)) & $60.8(8.3)$ & $58.0(8.8)$ & $58.9(8.2)$ & $\mathrm{p}<0.001$ \\
\hline Body mass index $\left(\mathrm{kg} / \mathrm{m}^{2}\right.$, mean (SD)) & $28.4(4.0)$ & $28.4(4.2)$ & $27.8(3.8)$ & $\mathrm{p}<0.001$ \\
\hline Systolic blood pressure (mm Hg, mean (SD)) & $139.8(21.8)$ & $139.4(20.5)$ & $137.5(20.3)$ & $p=0.006$ \\
\hline Diastolic blood pressure (mm Hg, mean (SD)) & $81.7(11.6)$ & $83.5(11.5)$ & $83.4(11.6)$ & $p<0.001$ \\
\hline Total cholesterol (mmol/l, mean (SD)) & $5.27(1.20)$ & $5.36(1.38)$ & $5.20(1.18)$ & $p=0.01$ \\
\hline HDL cholesterol (mmol/I, mean (SD)) & $1.18(0.31)$ & $1.18(0.31)$ & $1.21(0.32)$ & $p=0.03$ \\
\hline LDL cholesterol† (mmol/l, mean (SD)) & $3.31(1.08)$ & $3.35(1.23)$ & $3.23(1.02)$ & $p=0.09$ \\
\hline Triglycerides $\neq(\mathrm{mmol} / \mathrm{I}$, mean (SD)) & $1.79(1.21)$ & $1.84(1.16)$ & $1.73(1.04)$ & $p=0.10$ \\
\hline Glucose $\ddagger$ (mmol/l, mean (SD)) & $6.79(2.56)$ & $6.41(1.85)$ & $6.23(1.85)$ & $\mathrm{p}<0.001$ \\
\hline \multicolumn{5}{|l|}{ Women } \\
\hline Age $(y$, mean $(S D))$ & $62.2(8.3)$ & $59.8(8.3)$ & $59.5(8.6)$ & $\mathrm{p}<0.001$ \\
\hline Body mass index $\left(\mathrm{kg} / \mathrm{m}^{2}\right.$, mean $\left.(\mathrm{SD})\right)$ & $29.6(5.4)$ & $29.2(5.4)$ & $27.7(5.6)$ & $\mathrm{p}<0.001$ \\
\hline Systolic blood pressure (mm Hg, mean (SD)) & $145.6(24.2)$ & $142.2(23.7)$ & $139.9(23.4)$ & $p=0.17$ \\
\hline Diastolic blood pressure (mm Hg, mean (SD)) & $81.9(11.8)$ & $81.3(12.0)$ & $81.9(11.7)$ & $p=0.55$ \\
\hline Total cholesterol (mmol/I, mean (SD)) & $5.72(1.62)$ & $5.61(1.28)$ & $5.67(1.57)$ & $p=0.61$ \\
\hline $\mathrm{HDL}$ cholesterol (mmol/I, mean (SD)) & $1.36(0.35)$ & $1.37(0.36)$ & $1.45(0.41)$ & $p=0.005$ \\
\hline LDL cholesterol† (mmol/l, mean (SD)) & $3.58(1.30)$ & $3.43(1.16)$ & $3.38(1.22)$ & $p=0.09$ \\
\hline Triglycerides $\neq(\mathrm{mmol} / \mathrm{I}$, mean (SD)) & $1.79(1.08)$ & $1.81(0.92)$ & $1.73(1.08)$ & $p=0.21$ \\
\hline Glucose $\ddagger$ (mmol/l, mean (SD)) & $6.92(2.94)$ & $6.68(2.54)$ & $6.30(2.07)$ & $p=0.03$ \\
\hline
\end{tabular}

* $\mathrm{p}$ Value adjusted for age through analysis of covariance; taccording to Friedewald's formula $-\mathrm{LDL}$ cholesterol $=$ total cholesterol-HDL cholesterol-(triglycerides/5); ffor fasting subjects only. 
Table 3 Prelevance of risk factors (as categorical variables) by educational level in men and women

\begin{tabular}{|c|c|c|c|c|}
\hline & \multicolumn{3}{|l|}{ Educational level } & \multirow[b]{2}{*}{ p Value* } \\
\hline & Primary & Secondary & High & \\
\hline \multicolumn{5}{|l|}{ Men } \\
\hline Overweight† & $81.8 \%(1258 / 1537)$ & $81.1 \%(1176 / 1450)$ & $77.3 \%(942 / 1218)$ & $p=0.006$ \\
\hline Obesity $\ddagger$ & $32.8 \%(504 / 1537)$ & $28.3 \%(410 / 1450)$ & $25.2 \%(307 / 1218)$ & $p<0.001$ \\
\hline Smoking§ & $26.1 \%(403 / 1544)$ & $21.8 \%(316 / 1452)$ & $17.8 \%(217 / 1219)$ & $p<0.001$ \\
\hline Diabetes $\uparrow$ & $30.6 \%(415 / 1354)$ & $24.4 \%(319 / 1307)$ & $19.9 \%(211 / 1058)$ & $p<0.001$ \\
\hline High blood pressure ${ }^{* *}$ & $49.5 \%(762 / 1539)$ & $50.4 \%(732 / 1451)$ & $45.6 \%(556 / 1219)$ & $p=0.009$ \\
\hline High total cholesterolt† & $55.1 \%(825 / 1497)$ & $57.8 \%(773 / 1337)$ & $53.2 \%(611 / 1148)$ & $p=0.08$ \\
\hline Low HDL cholesterolł¥ & $27.9 \%(417 / 1496)$ & $27.1 \%(362 / 1336)$ & $25.0 \%(287 / 1150)$ & $p=0.11$ \\
\hline \multicolumn{5}{|l|}{ Women } \\
\hline Overweight† & $80.7 \%(530 / 657)$ & $76.4 \%(323 / 423)$ & $65.4 \%(140 / 214)$ & $p<0.001$ \\
\hline Obesity $\ddagger$ & $41.6 \%(273 / 657)$ & $37.4 \%(158 / 423)$ & $29.4 \%(63 / 214)$ & $p=0.006$ \\
\hline Smoking§ & $16.8 \%(111 / 660)$ & $19.5 \%(83 / 425)$ & $16.3 \%(35 / 215)$ & $p=0.43$ \\
\hline Diabetes & $33.0 \%(186 / 564)$ & $28.5 \%(104 / 365)$ & $21.8 \%(39 / 179)$ & $p=0.03$ \\
\hline High blood pressure** & $59.2 \%(389 / 657)$ & $53.3 \%(226 / 424)$ & $51.9 \%(111 / 214)$ & $p=0.51$ \\
\hline High total cholesterolt† & $67.5 \%(416 / 616)$ & $66.9 \%(261 / 390)$ & $67.5 \%(137 / 203)$ & $p=0.98$ \\
\hline Low HDL cholesterolł‡ & $11.9 \%(73 / 612)$ & $12.8 \%(50 / 390)$ & $10.0 \%(20 / 200)$ & $p=0.60$ \\
\hline
\end{tabular}

primary to secondary and high education in overweight, obesity, and prevalence of diabetes, in both sexes. The prevalence of current smoking decreased significantly from primary to secondary and high education in men, but not in women, whereas the highest smoking prevalence was only found in men with primary education. A negative trend in prevalence of high blood pressure was found, however it only reached statistical significance in men. High total and low HDL cholesterol have not differed by educational level reached.

Adjusted odds ratios and 95\% confidence intervals for the association between education and categorical risk factors are given in table 4 . Taking high education as reference, the lower education levels (secondary and primary education) increased the relative risk of all factors, with exception of low HDL. The largest risk increase was observed in smoking (OR 1.44 and 2.00, for secondary and primary education, respectively) and in overweight (OR 1.44 and 1.58, in secondary and primary education, respectively).

\section{Drugs used for secondary prevention}

Reported medical treatment is presented in table 5. No differences by education were found in antiplatelets and in antihypertensive drugs in general. However, patients with highest education were more often treated with $\beta$ blockers and moreover, with lipid lowering drugs, particularly with statins. Patients with primary education were more often treated with calcium antagonists and moreover, with antidiabetic drugs. The effectiveness of antihypertensive treatment (proportion of patients, who reached target values 140/90 $\mathrm{mm} \mathrm{Hg}$ ) somewhat increased from primary to secondary and high education, with borderline significance $(p=0.06)$. No differences were observed in terms of lipid lowering and control of glycaemia or diabetes (table 6).

\section{DISCUSSION}

Both, the EUROASPIRE I and II, studies have already shown a high prevalence of modifiable lifestyle related risk factors like smoking and obesity, and biomedical factors like hypertension, hyperlipidaemia, and diabetes in clinical coronary patients. These studies have moreover demonstrated poor implementation of recommended drug treatments in coronary patients, in all participating European countries. ${ }^{91012}$

This study shows that the level of education is in a significant negative association with virtually all followed up cardiovascular factors and also moreover, with the use and effectiveness of medical interventions. The social environment characterised by social class, income, occupation, and education is known to be related to a large range of diseases, including coronary heart disease and hypertension. ${ }^{13}$ A recent study in different US states has shown that lack of high school education is a powerful predictor of mortality

Table 4 Odds ratios (calculated from logistic regression models) for coronary heart disease risk factors by educational level

\begin{tabular}{|c|c|c|c|}
\hline & \multicolumn{3}{|l|}{ Educational level } \\
\hline & Primary & Secondary & High* \\
\hline Overweight† & $1.58(1.32$ to 1.90$)$ & $1.44(1.20$ to 1.72$)$ & 1 \\
\hline Obesity $\ddagger$ & 1.64 (1.39 to 1.93$)$ & 1.26 (1.06 to 1.48$)$ & 1 \\
\hline Smoking§ & 2.00 (1.65 to 2.43$)$ & $1.44(1.19$ to 1.76$)$ & 1 \\
\hline Diabetes & 1.25 (1.03 to 1.52$)$ & $1.05(0.86$ to 1.28$)$ & 1 \\
\hline High blood pressure** & $1.23(1.06$ to 1.44$)$ & 1.31 (1.12 to 1.53$)$ & 1 \\
\hline High total cholesterolt† & 1.22 (1.04 to 1.43$)$ & 1.21 (1.03 to 1.42$)$ & 1 \\
\hline Low HDL cholesterol $\ddagger \ddagger$ & 1.11 (0.92 to 1.34$)$ & 1.02 (0.84 to 1.22 ) & 1 \\
\hline
\end{tabular}

*Odds ratio and $95 \%$ confidence intervals adjusted for age, gender, diagnosis, centre, and furthermore for body mass index through logistic regression modelling, taking high education as reference (that is, relative risk of high education is equal to 1). $+B M l \geqslant 25 \mathrm{~kg} / \mathrm{m}^{2} ; \ddagger B M l \geqslant 30 \mathrm{~kg} / \mathrm{m}^{2} ;$ sself reported current smoking and/or carbon monoxide in breath $>10$ ppm; 'self reported diabetes and/or fasting glucose $\geqslant 7 \mathrm{mmol} / \mathrm{l}$; ** systolic blood

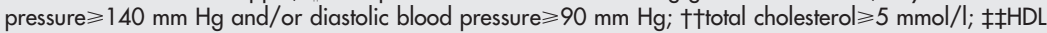
cholesterol $<1 \mathrm{mmol} / \mathrm{l}$. 
Table 5 Use of secondary preventive medication by educational level in both genders

\begin{tabular}{lllll}
\hline \multicolumn{4}{c}{ Educational level } & \\
\cline { 2 - 4 } & $\begin{array}{l}\text { Primary } \\
(\mathbf{n}=1544)\end{array}$ & $\begin{array}{l}\text { Secondary } \\
(\mathbf{n}=1451)\end{array}$ & $\begin{array}{l}\text { High } \\
(\mathbf{n}=1220)\end{array}$ & p Value* \\
\hline Antiplatelet drugs & 84.7 & 86.6 & 88.1 & $\mathrm{p}=0.54$ \\
Any antihypertensive drugs & 88.0 & 87.3 & 84.2 & $\mathrm{p}=0.08$ \\
$\beta$ blockers & 60.7 & 63.7 & 64.9 & $\mathrm{p}=0.03$ \\
ACE inhibitors & 38.2 & 38.0 & 39.1 & $\mathrm{p}=0.80$ \\
Diuretics & 19.3 & 15.5 & 15.2 & $\mathrm{p}=0.45$ \\
Calcium antagonists & 29.9 & 24.7 & 20.7 & $\mathrm{p}<0.001$ \\
Any lipid lowering drugs & 58.1 & 61.3 & 64.6 & $\mathrm{p}<0.001$ \\
Statins & 52.1 & 55.4 & 61.0 & $\mathrm{p}<0.001$ \\
Antidiabetic drugs & 16.6 & 13.6 & 10.1 & $\mathrm{p}<0.001$ \\
\hline * $\mathrm{p}$ Value adjusted for age and gender through logistic regression modelling. Data shown as percentages.
\end{tabular}

variation and income inequality. ${ }^{14}$ Similar findings were already published three decades ago, by Hinkle et al, ${ }^{3}$ who found, that managers in high position, but without formal college or university education had higher coronary mortality, than those with a high formal education grade attained.

Because the median of years spent at school in different countries considerably varied and overlapped, we arbitrarily divided the sample by educational level reached into primary secondary and high education categories. Both items (number of years, spent at in full time study and highest education reached) were included in the patient interview questionnaire. The reported educational level reached is probably a better proxy for individual SES, than number of years spent at school, because higher educational level results generally in higher personal income and corresponding SES. ${ }^{1}$ Income, as a measure of SES could not be used in this study, because of large economical differences among participating countries.

The Minnesota heart survey has previously shown that education was inversely related to blood pressure, cigarette smoking, BMI, and summary of risk score, for both men and women. ${ }^{15}$ The Framingham study also found adverse levels of coronary heart disease risk factors in people with low educational attainment. ${ }^{16}$ Kunst et al observed that mortality from CHD was strongly related to occupational class in England and Wales, Ireland, Finland, Sweden, Norway and Denmark, but not in France, Switzerland and Mediterranean countries. ${ }^{17}$ These differences between countries were contributed to variations of disease specific risk factors, like smoking or dietary habits.

Education and occupation was also observed to be in association with total mortality, coronary mortality, morbidity, and coronary risk in Eastern Central European countries. $^{18-21}$ While the coronary risk factors in Pol-MONICA study ${ }^{18}$ were lower in farmers and manual workers than in non-manual workers, the reverse was found in Czech MONICA study ${ }^{22}$ and also, in a Czech industrial population. ${ }^{5}$ The education was found to be in a negative association with total mortality and coronary morbidity. ${ }^{19}{ }^{20}$ Similarly, negative association of education level appeared with smoking, blood pressure, and total cholesterol. ${ }^{21} 23$ Cigarette smoking was observed a main risk factor particularly related to educational status in 12 countries. ${ }^{24}$ There were significantly more smokers among men and women with low education, mainly in UK and Norway. For men the reverse was only found in Portugal, while woman behaved differently. Again, women with low education smoked more in Finland, the Netherlands, Norway, Germany, UK, Sweden, and Switzerland, but less in Spain, Portugal, and in the age group over 45 years also in France and Italy. On the whole, virtually no differences existed in risk factors distribution and their control between Western European and post-communist countries. ${ }^{9}$ The costs of drug treatment were entirely or partly covered by health insurance in all participating countries. Therefore, the use of recommended drugs depended more on implementation of guidelines and compliance of patients, than on economical inequalities among countries.

The study has several limitations. Notably, EUROASPIRE was not designed as an epidemiological study. It was a pragmatic survey to estimate how effectively the secondary measures are being used across Europe. Therefore some hospital diagnoses for AMI and ischaemia might not always meet the standard diagnostic criteria used by WHO. All cases with these diagnostic labels were included, as all these patients should be appropriately managed in relation to lifestyle intervention, management of other risk factors, and use of prophylactic drug treatments. Furthermore, unlike

Table 6 Proportion of patients who reached targets values for blood pressuret, cholesterolf, and glucose§

\begin{tabular}{|c|c|c|c|c|}
\hline & \multicolumn{3}{|c|}{ Educational level } & \multirow[b]{2}{*}{ p Value* } \\
\hline & Primary & Secondary & High & \\
\hline \multicolumn{5}{|l|}{ Blood pressure } \\
\hline No antihypertensive drugs & 55.1 & 49.0 & 54.6 & $p=0.14$ \\
\hline Antihypertensive drugs & 46.6 & 48.9 & 53.3 & $p=0.06$ \\
\hline \multicolumn{5}{|l|}{ Total cholesterol¥ } \\
\hline No lipid lowering drugs & 29.5 & 26.0 & 26.9 & $p=0.10$ \\
\hline Lipid lowering drugs & 49.8 & 49.0 & 54.4 & $p=0.14$ \\
\hline \multicolumn{5}{|l|}{ Glucose§ } \\
\hline Diabetes not reported & 89.0 & 88.5 & 90.8 & $p=0.16$ \\
\hline Self reported diabetes & 25.2 & 29.8 & 29.9 & $p=0.10$ \\
\hline
\end{tabular}




\section{Policy implications}

- Low education patients probably need different strategies to improve the implication of secondary preventive measures.

PTCA, CABG, and AMI, the term acute ischaemia remained poorly validated and only relied on physicians' judgement in discharge summary. We had no information about educational status of those who died before being recruited in the study. We are just reporting on a sample of European coronary patients, who have survived their index event for at least six months. We do not show or mention any data gathered in the time of hospital admission or during hospital stay. All information used was obtained at interview of surviving patients. Observed differences in risk factors and treatment are not representative for entire populations of participating countries, because clinical patients were recruited from large cardiologic centres or university hospitals in each country. The implementation of secondary preventive measures would be supposed far more neglected in the real medical world. Therefore, if the selection of hospitals would be more representative for country-wide health services of participating countries, the differences between educational groups would probably be more evident.

The EAI and EAII data have shown that evidence based, secondary prevention measures are widely underused in Europe. ${ }^{7810}$ This study indicates the need to deliver special attention to coronary patients with low education to favour preventive lifestyle changes and compliance with evidence based drug treatment. The implementation of coronary prevention guidelines is a difficult task. It would probably need different approaches adapted to educational status of patients to improve results.

\section{ACKNOWLEDGEMENTS}

The EUROASPIRE II survey was carried out under the auspices of the European Society of Cardiology, Euro Heart Survey programme. The authors are particularly grateful to all the patients who participated in the survey. The authors are also grateful to the expert scientific committee, coordinating and data management centre, all investigators and personnel participating on this survey (as listed in appendix, see journal web site http://www.jech.com/supplemental).

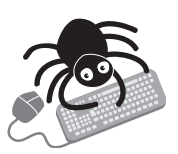

A full list of the investigators and personnel participating in this survey is available on the journal web site (http://www.jech.com/supplemental).

\section{Authors' affiliations}

O Mayer Jr, J Šimon, Centre of Preventive Cardiology, 2nd Department of Internal Medicine, Medical Faculty, Charles University, Pilsen, Czech Republic

J Heidrich, Institute of Epidemiology and Social Medicine, University of Münster, Germany
D V Cokkinos, Onassis Cardiac Surgery Center, Athens, Greece D De Bacquer, Department of Public Health, Ghent University, Belgium

\section{REFERENCES}

1 Winkleby MA, Jatulis DE, Frank E, et al. Sociecomic status et health: How education income and occupation contributed to risk factors for cardiovascular disease. Am J Public Health 1992;82:816-20

2 Liu K, Cedres LD, Stamler J, et al. Relationship of education to major risk factor and death from coronary heart disease, cardiovascular diseases and all causes. Circulation 1982;66:308-14.

3 Hinkle L, Whitney L, Lehman E, et al. Occupation, education and coronary heart disease. Science 1968;161:238-40.

4 Rose G, Marmot MG. Social class and coronary heart disease. Br Heart J $1981 ; 45: 13-17$.

5 Šimon J, Cajzl L, Křižanovská $M$, et al. Occupation and education in relation to risk factors of ischeamic heart disease in the male industrial population. Cor Vasa 1986:28:167-76.

6 Kilander L, Berglund L, Boberg M, et al. Education, lifestyle and mortality from cardiovascular disease and cancer. A 25 -year follow-up of Swedish 50-yearold men. Int J Epidemiol 2001;30:1119-26.

7 Cavelaars AEJM, Kunst AE, Geurts JJM, et al. Differences in selfreported morbidity by educational level: a comparison of 11 Western European countries. J Epidemiol Community Health 1998;52:219-27

8 Hemingway H, Marmot M. Psychosocial factors in the aetiology and prognosis of coronary heart disease: systematic review of prospective cohort studies. BMJ 1999:318:1460-7.

9 EUROASPIRE II Group. Lifestyle and risk factor management and use of drug therapies in coronary patients from 15 countries. Principal results from EUROASPIRE II. Eur Heart J 2001 ;22:554-72.

10 EUROASPIRE I and II Group. Coronary prevention guidelines- the clinical reality. A comparison of EUROASPIRE I and II surveys in 9 countries. Lancet 2001;357:995-1001.

11 Wood D, De Backer G, Faergeman D, et al. Prevention of coronary heart disease in clinical practice. Recommendations of the Second Joint Task Force of European and other Societies on coronary prevention. Eur Heart $J$ 1998; 19:1434-503.

12 EUROASPIRE Study Group. EUROASPIRE. A European Society of Cardiology survey of secondary prevention of coronary heart disease: principal results, Eur Heart J 1997; 18:1569-82.

13 McCulloch A. Social environments and health: cross sectional national survey. BMJ 2001;323:208-9.

14 Muller A. Education, income inequality, and mortality: a multiple regression analysis. BMJ 2002;324:23-5

15 Luepker RV, Rosamond WD, Murphy R, et al. Progression of coronary artery disease: socio-economic status and coronary heart disease risk factor trends. The Minnesota Heart Survey. Circulation 1993;88:2172-9

16 Garrison RJ, Gold RS, Wilson PWF, et al. Educational attainment and coronary heart disease risk: the Framingham Offspring Study. Prev Med 1993;22:54-64

17 Kunst AE, Groenhof F, Mackenbach JP. Occupational class and cause specific mortality in middle age men in 11 European countries: comparison of population based studies. BMJ 1998:316:636-41.

18 Pajak A. Job and blood lipids. Findings of POL-MONICA Krakow study. Acta Cardiol 1994:49:343-5.

19 Rosolová H, Šimon J, Šefrna F. Impact of cardiovascular risk factors on morbidity and mortality in Czech middle-aged men: Pilsen Longitudinal Study. Cardiology 1994:85:61-8.

20 Bobák M, Hertzman C, Škodová Z, et al. Own education, current conditions, parental material circumstances, and risk of myocardial infarction in former communist countries. J Epidemiol Community Health 2000;54:91-6.

21 Rosolová H, Šimon J. The influence of education on the risk profile in Czech men and women. Pilsen Longitudinal Study. Acta Cardiol 1994:49:369-71.

22 Bobák M Škodová Z, Píša Z. Vztah mezi vzděláním a prevalencí kardiovaskulárních rizikových faktorů [Relationship between education and prevalence of cardiovascular risk factors.] [In Czech, abstract in English.] Cas Lek Ces 1994;133:627-32.

23 Bobák M, Hertzman C, Škodová Z, et al. Socioeconomic status and cardiovascular risk factors in the Czech Republic. Int J Epidemiol 1999:28:46-52.

24 Cavelaars AEJM, Kunst AE, Geurts JJM, et al. Educational differences in smoking: international comparison. BMJ 2000;320:1102-7. 